\title{
From Longitudinal Gastric Resection to Sleeve Gastrectomy-Revival of a Previously Established Surgical Procedure
}

\author{
Hans-Ullrich Spiegel • Sebastian Skawran
}

Received: 11 April 2010 /Accepted: 5 August 2010 /Published online: 20 August 2010

(C) The Author(s) 2010. This article is published with open access at Springerlink.com

\begin{abstract}
Introduction Sleeve gastrectomy is becoming increasingly popular within bariatric surgery. Initially introduced as a component of complex interventions and later as part of a two-stage operation in high-risk patients, the procedure is now more common as one-stage operation and subject of avid scientific discussion. However, the concept of longitudinal gastric resection is not new. The procedure was already established in ulcer surgery but soon faded into insignificance. This article aims to trace the historical development of resection of the greater curvature with particular reference to its origin in ulcer and bariatric surgery. The contribution of ulcer surgery to modern sleeve gastrectomy is highlighted. Furthermore, the current value of sleeve gastrectomy within the spectrum of bariatric surgical procedures will be discussed. Relevant medical literature from PubMed to April 2010 was reviewed.

Discussion Besides bariatric surgery modern sleeve gastrectomy has one more so far largely neglected origin: segmental and later longitudinal gastric resection used in ulcer surgery. Experience and achievements from ulcer surgery simplified and facilitated development of sleeve gastrectomy which is not the desired universal procedure for bariatric surgery but certainly an attractive treatment option. It should be performed in a more standardized manner and with due regard to future longterm results.
\end{abstract}

Keywords Segmental gastric resection - Tube gastrectomy Longitudinal gastric resection $\cdot$ Sleeve gastrectomy.

Bariatric surgery

\section{Introduction}

Obesity is gradually turning into an epidemic condition throughout the world and has become a social, psychological, and economic burden of growing proportions. ${ }^{1,2}$ It is associated with a large number of concomitant diseases (including type-2 diabetes, cardiovascular and respiratory diseases, dyslipidemia, and elevated risk of cancer) and also markedly shortens the obese person's life expectancy.,

H.-U. Spiegel $(\bowtie) \cdot$ S. Skawran

Department of General and Visceral Surgery,

Surgical Research, University Hospital,

Waldeyer Str. 1,

48149 Muenster, Germany

e-mail: spiegeh@uni-muenster.de
Due to the limited options and especially the poor longterm results of conservative treatment, the surgical approach of bariatric surgery has been established in the last few decades. ${ }^{3}$

A bariatric procedure is considered to be indicated in adult patients with morbid obesity $\left(\mathrm{BMI} \geq 40 \mathrm{~kg} / \mathrm{m}^{2}\right)$ or a $\mathrm{BMI} \geq$ $35 \mathrm{~kg} / \mathrm{m}^{2}$ with additional comorbidities. ${ }^{5,6}$ Long-term results of the surgical approach have been convincing in terms of reduced morbidity and mortality as well as enhanced quality of life. ${ }^{7,8}$ Due to growing experience and the introduction of the endoscopic technique, the procedures have become increasingly safe and can be performed more easily by the use of modern stapling devices. Therefore, bariatric surgery is even considered in adolescents with a high-risk profile or in patients with $\mathrm{BMI}<35 \mathrm{~kg} / \mathrm{m}^{2}$. 9,10

Several surgical procedures have been developed over time and nearly all of them are currently performed by the laparoscopic approach. A distinction has been made between restrictive, malabsorptive, combined restrictive and malabsorptive, and electrical procedures for gastric stimulation. This diversity and the ongoing modifications of 
the procedures highlight the fact that there is no ideal procedure for widespread application. The quality of the respective procedures is no longer established by the previously used primary parameter of "excess weight loss," but by the procedure's potential to maintain sufficient weight reduction on a long-term basis while ensuring minimal mortality and morbidity.

In recent times, one procedure has become increasingly popular in obesity surgery, namely longitudinal gastric resection or sleeve gastrectomy. It was initially used as a part of complex interventions (including biliopancreatic diversion with duodenal switch) and later as a two-step bridging procedure in high-risk patients prior to final intervention, but was then established as a stand-alone procedure and is currently a subject of avid scientific discussion.

The current concept of tube gastrectomy by resection of the greater curvature is not new in bariatric surgery. It is largely neglected that segmental and especially longitudinal gastric resection were developed and used in ulcer surgery. ${ }^{11-13}$ Following the introduction of adequate conservative drug therapies, ulcer surgery is now almost exclusively used as an emergency procedure. Subsequently longitudinal gastric resection faded into insignificance. However, longitudinal gastric resection can be regarded as precursor of modern tube gastrectomy, which is now known as sleeve gastrectomy and is experiencing a revival in obesity surgery.

The aim of the present review is to trace the historical development of the current longitudinal gastric resection on the basis of its origins in ulcer and bariatric surgery and to elucidate the subject with suitable illustrations. Furthermore the contribution of historic ulcer surgery to modern bariatric surgery and in particular sleeve gastrectomy is demonstrated. Finally, contemporary sleeve gastrectomy, its complications, and especially the current value of this procedure in the therapy spectrum of bariatric surgery will be discussed on the basis of major recent studies.

We conducted an extensive literature review and evaluation for this purpose.

(a) Development of longitudinal gastric resection in ulcer surgery

The advancing use of gastric surgery is a milestone in the evolution of abdominal surgery. The first gastric resection procedures were performed by J. Péan and L. Rydygier in 1879 and 1880, but with lethal outcomes. $^{14,15} \mathrm{~T}$. Billroth is known as the pioneer of gastric surgery and its scientific foundation. In 1881, he performed the first successful gastric resection in a patient with a pyloric carcinoma. ${ }^{16}$ His work served as the starting point for classical gastric resection procedures such as Billroth I and Billroth II (first performed on a human patient in 1885), depending on the manner of restoration of the gastrointestinal passage. These procedures became essential elements of every general surgeon's repertoire, particularly for ulcer treatment.

K. Schwarz's discovery of the concept of "no ulcers without acids" in 1910 had a decisive impact on the development of gastric resection procedures. ${ }^{17}$ After this time, the aim of upcoming ulcer surgery was to reduce acid levels adequately in order to avoid recurrences. The purpose of the first segmental gastric resection procedures was to perform wedge- or V-shaped ulcer excision; these were conducted as early as 1897 by J. Mikulicz, 1904 by B. Riedel, and 1929 by F.G. Connell. ${ }^{18-20}$ However, initially the outcome of these procedures was impeded due to considerable side effects like gastric emptying disorders. ${ }^{11}$ Segmental gastric resection was greatly modified by O.H. Wangensteen who, in 1952, investigated the surgical procedures in great depth and resolved the problem of postoperative gastric emptying disorders by performing additional pyloroplasty. ${ }^{21}$ The technique was developed further by D.J. Ferguson (1960), F. Largiadèr (1971), and T. Sekine (1975). ${ }^{22-24}$ The outstanding aspect of these advancements was preservation of antral innervation in order to prevent the post-gastrectomy syndrome. Again it was O.H. Wangensteen who encouraged to make use of longitudinal resection of the greater curvature. Influenced by his experiences in segmental gastric resection with its undesirable side effects (among others dumping syndrome), he searched for an "acceptable operation" for ulcer treatment. He was aware of the fact that gastric parietal cells, which are responsible for the production of HCL, are most dense in the corpus region-lengthwise along the greater curvature. ${ }^{11,25}$ When performing the previous classical resection procedures (including BI and BII resections and segmental gastric resection), portions of the stomach were removed at right angles to its conceived longitudinal axis. However, performing gastric resection along the longitudinal axis was considered even earlier by F. Neugebauer, A.A. Strauss, and V. Schmieden in 1921 and $1924 .^{26-28}$ In contrast to Wangensteen they performed resection along the lesser curvature to remove the ulcer itself, independent of acid reduction. However, Wangensteen performed the first experiments of longitudinal resection along the greater gastric curvature to reduce acidity of gastric juice in 1940. In some cases, he added a gastrojejunostomy at the antral gastric end (Fig. 1)..$^{25,29}$ Based on promising results, he subsequently evolved his method of tubular gastric resection with additional transverse gastroplasty in order to accomplish a gastric reservoir function. Wangensteen started applying this technique in 90 patients with duodenal ulcers and reported convincing results. ${ }^{11}$ However, after performing further animal experi- 


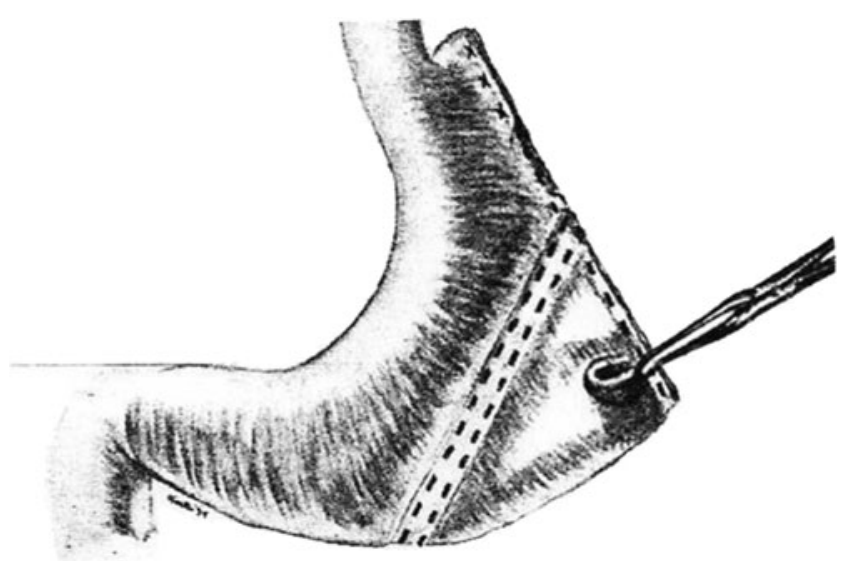

Fig. 1 As early as in 1940, O.H. Wangensteen performed longitudinal gastric resection to excise acid-producing regions of the $\operatorname{stomach}^{29}$

ments in 1957 , he revised his initially positive verdict about the operation. The acid response of the stomach after test meals was many-fold higher in animals subjected to tubular resection than in those that had undergone segmental gastric resection. Wangensteen and colleagues attributed this phenomenon to the preservation of antral innervation and the resulting higher gastrin and acid secretion of the residual parietal cells. He concluded that tubular gastric resection should be viewed with caution and stopped using this technique. ${ }^{30}$ It is noteworthy that L. Leger and L. Deloyers made use of tubular or longitudinal resection without supplementary transverse gastroplasty. ${ }^{31,32}$

In 1966, M. Saegesser introduced the theoretical construct of "ideal gastric resection" including resection of the corpus/ fundus and the antrum, in combination with a selective postbranchial vagotomy and pylorotomy (Fig. 2). ${ }^{33}$ By performing longitudinal resection of the greater curvature, he intended to reduce acid secretion while preserving gastric reservoir function and the natural food passage. In 1988-1990, J.

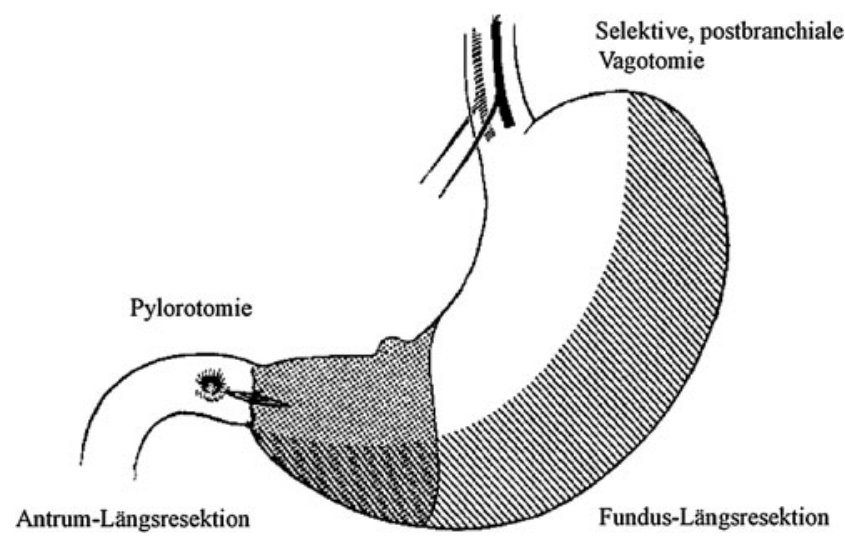

Fig. 2 In 1966, M. Saegesser propagated his construct of "ideal gastric resection" with longitudinal resection of the fundus and the antrum, selective post-branchial vagotomy, and pylorotomy ${ }^{33}$
Hauss and H.U. Spiegel focused on this construct and Wangensteen's results, and made further developments. ${ }^{12,34}$ However, they dispensed with the vagotomy and pylorotomy demanded by Saegesser because they believed that partial resection of the antrum and postoperative reduction of parietal cells would achieve sufficient acid reduction. In animal experiments, they achieved a $70 \%$ reduction of acid secretion in the presence of a normal serum gastrin response (Fig. 3). ${ }^{34}$ In 1993, subsequent animal studies using this model showed a linear correlation between the reduction of parietal cells and acid reduction levels. ${ }^{35}$ Spiegel's model was based on longitudinal gastric resection on the side of the greater curvature using a stapler and a gastric probe as guide rail. Thus, he created a "modern" gastric tube (Fig. 4a, b). ${ }^{35}$ Subsequently, the procedure was used in the clinical setting with promising results. 13,36

The use of gastric resection procedures in gastroduodenal ulcer surgery entered a phase of stagnation and regression after this time. The decisive change which led to the renunciation of conventional resection procedures was the fact of advancing knowledge about the pathogenesis of ulcers, particularly the introduction of $\mathrm{H}_{2}$ receptor antagonists at the end of the 1970s, the introduction of proton pump inhibitors at the end of the 1980s, and the discovery of Helicobacter pylori in 1982. These developments had an equally strong impact on various vagotomy procedures for denervation, which were used less, and less in ulcer surgery.

Currently, the use of gastroduodenal ulcer surgery is confined to classical ulcer complications (hemorrhage, perforation, penetration, pyloric stenosis) and to exclude malignant tumors in cases of ulcers refractory to conservative treatment. The clinical use of longitudinal gastric resection was therefore becoming increasingly insignificant soon after being established as a treatment option. This was accompanied by lack of sufficient data or further relevant publications.

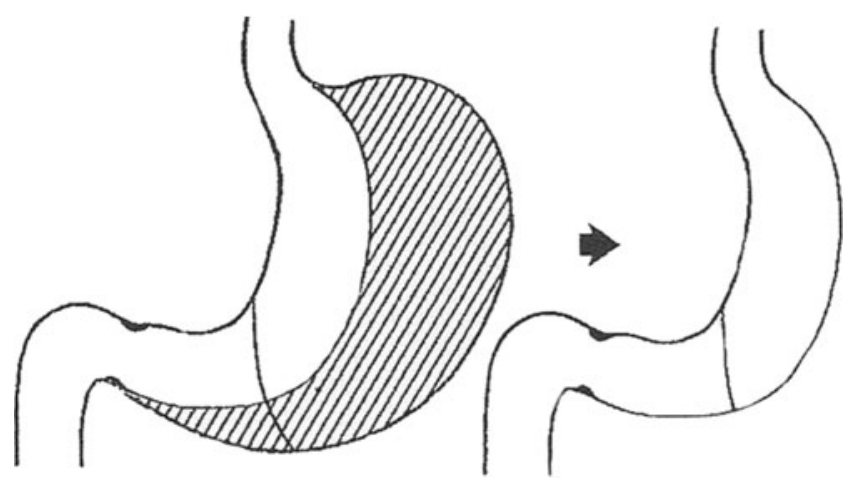

Fig. 3 In 1988, J. Hauss and H.U. Spiegel presented a modified longitudinal resection model without vagotomy and pyolorotomy and reported significant acid reduction ${ }^{34}$ 
Fig. 4a and b In 1993, H.U. Spiegel used longitudinal gastric resection in a large study focused on the treatment of ulcers. He utilized a gastric probe as guide rail (a) and a linear stapler (b) to create a "modern" gastric tube $\mathrm{e}^{35}$
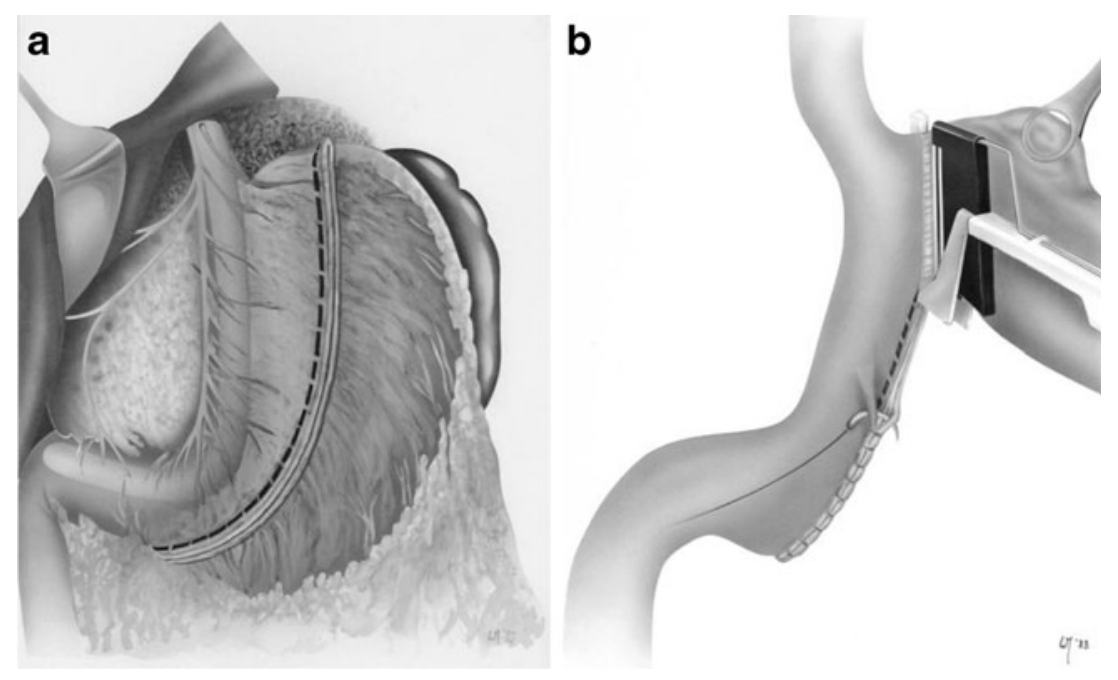

(b) Development of longitudinal gastric resection in bariatric surgery

A review of the essential steps in the historical development of bariatric surgery is helpful in order to understand how longitudinal gastric resection appeared as sleeve gastrectomy within the modern therapy options. Obesity surgery started with purely malabsorptive procedures, moved on to combined malabsorptive and restrictive procedures, and finally consisted of mainly restrictive procedures. The first published bariatric intervention was a malabsorptive jejunoileal bypass performed by A.J. Kremen and coworkers in $1954 .{ }^{37}$ Numerous modifications followed, particularly in respect of location and type of the anastomosis. ${ }^{38}$ A significant reduction in weight was achieved. However, many of these procedures were accompanied by serious side effects (including diarrhea, hepatic cirrhosis, and electrolyte imbalance) and did not prevail in the long term. ${ }^{2,39}$

Gradually, bariatric interventions were increasingly focused on the stomach. Various methods were used to reduce gastric volume and stimulate satiety. Furthermore, a malabsorptive component was additionally employed to create a gastrointestinal bypass. In 1967, E.E. Mason submitted the first report of a gastric bypass after horizontal division of the stomach with re-anastomosis of its proximal portion by the use of a raised jejunal loop. ${ }^{40}$ Again, numerous variations regarding pouch size or replacing division of the stomach by applying a horizontal row of clip sutures followed. The Roux-en-Y gastric bypass published by W.O. Griffen in 1977, using a gastrojejunostomy, and Y-Roux reconstruction, while avoiding bile reflux, provided the advantage of a tension-free anastomosis. ${ }^{41}$ After further modifications (particularly in respect of placement of the pouch and the length of the respective loops), this technique evolved into a standard procedure in bariatric surgery, especially in the USA, because of its very favorable ratio between weight reduction and side effects. ${ }^{42}$

A further noteworthy milestone in the development of bariatric surgery is biliopancreatic diversion which was developed by N. Scopinaro in 1979. Biliopancreatic diversion is also a combination of a malabsorptive procedure and a restrictive component. Scopinaro combined horizontal gastric resection with closure of the duodenal stump and a gastrojejunostomy while creating a "common tract" by jejunoileostomy to exclude large portions of the small bowel (Fig. 5). ${ }^{43}$ Scopinaro initially varied the lengths of the three segments of the small bowel. Subsequently a "common tract" about $50 \mathrm{~cm}$ in length and an "alimentary tract" about $250 \mathrm{~cm}$ length became established. ${ }^{2,44}$ The disadvantages of the procedure include

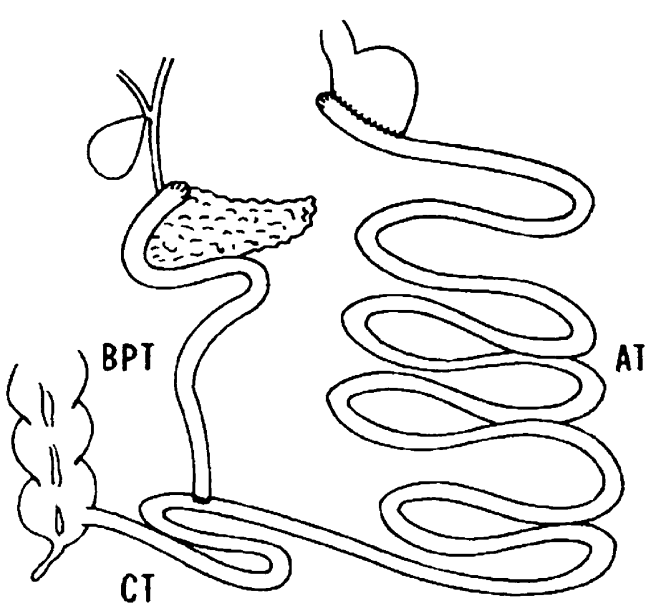

Fig. 5 In 1979, N. Scopinaro introduced his procedure of biliopancreatic diversion. He performed horizontal partial resection of the stomach with closure of the duodenal stump, gastrojejunostomy, and a jejunoileal anastomosis to create an "alimentary tract" $(A T)$, a "biliopancreatic tract" $(B P T)$, and finally, a "common tract" $(C T)^{99}$ 
malassimilation of fat and deficiency syndromes such as those of protein, iron, or vitamins. ${ }^{44,45}$

In 1973, E.E. Mason and K.J. Printen reported the first purely restrictive procedure by incomplete horizontal division of the stomach while forming a conduit on the side of the greater curvature. However, the technique did not gain wide acceptance because of poorly sustained weight reduction. ${ }^{46}$ Subsequent variations were used to achieve a reduction of gastric volume but were not successful due to dilatation of the gastric pouch. ${ }^{2,38}$ This problem was finally resolved in 1982, again by E.E. Mason, who introduced vertical gastroplasty with creation of a pouch on the side of the lesser curvature by placing a vertical clip suture and providing additional reinforcement with a distal polypropylene mesh ring. ${ }^{47}$ Finally, restriction of the stomach by the use of a gastric band was developed in 1978, initially without the option of being adjustable. ${ }^{48}$ The adjustable gastric band initially introduced by L.I. Kuzmak in 1986 was modified further and is the second most commonly used procedure in obesity surgery these days. $^{38,49}$

The modern procedure of longitudinal gastric resection or sleeve gastrectomy was incorporated quite late in the repertoire of obesity surgery. In 1993, P. Marceau and coworkers modified biliopancreatic diversion which had been introduced by N. Scopinaro and replaced horizontal gastric resection with longitudinal gastric resection on the side of greater curvature, combined with preservation of the pylorus, and additionally doubled the length of the "common tract" to $100 \mathrm{~cm}^{44}$ Initially the small bowel was anastomosed to the proximal duodenum with additional placing of a distal row of clip sutures without transsection of the duodenum. However, this procedure was frequently associated with insufficiency of clip sutures, followed by a renewed increase in weight. ${ }^{44}$ The problem was resolved by the advancements made by D.W. and D.S. Hess, based on T.R. DeMeester. ${ }^{50,51}$ In 1998, they introduced biliopancreatic diversion with placement of a duodenal switch under postpyloric transsection of the duodenum and subsequent anastomosis with the alimentary loop. The biliopancreatic loop was anastomosed in the region of the distal ileum by creating a 50 - to 100 -cm-long "common channel," again anastomosed to the alimentary loop. They also utilized tube gastrectomy as a restrictive component (Fig. 6) ${ }^{51}$ In conjunction with the development of minimally invasive surgery, the first laparoscopic tube gastrectomy was performed in the course of biliopancreatic diversion with a duodenal switch in 2000 (Fig. 7). ${ }^{52}$

One of the milestones in the development of tube gastrectomy was the concept of the Magenstrasse and Mill operation. Developed with the aim of devising a physiological bariatric procedure while avoiding implant-related complications (such as those encountered with an adjust-

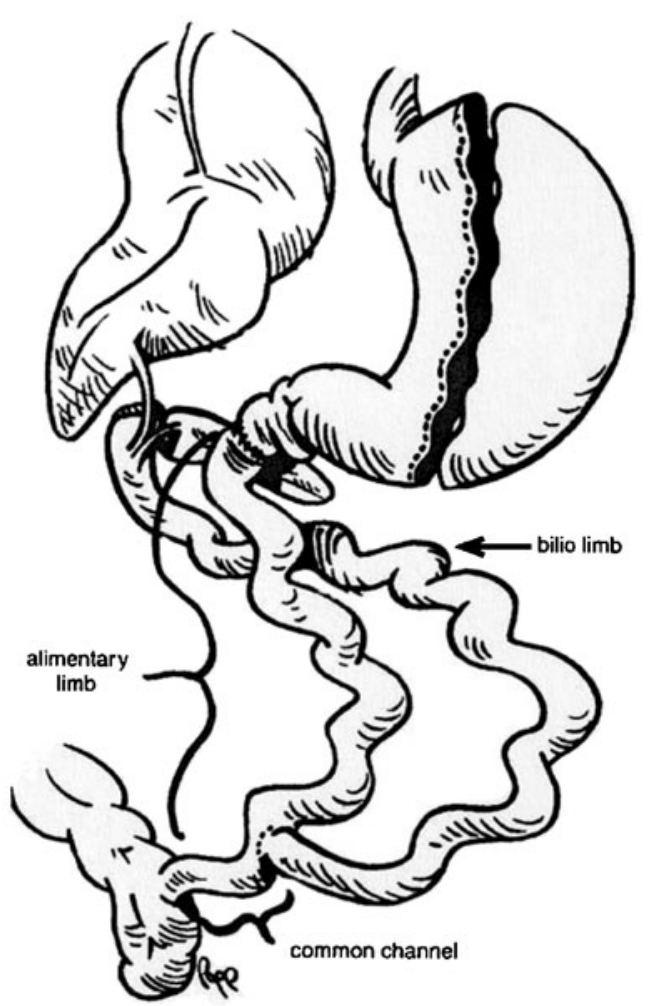

Fig. 6 In 1998, D.W. and D.S. Hess published biliopancreatic diversion with an additional duodenal switch. While preserving the pylorus they also created a biliopancreatic, an alimentary, and a common small bowel segment. Using longitudinal gastric resection, they established a combined restrictive-malabsorptive procedure ${ }^{51}$

able gastric band or vertical banded gastroplasty) and reducing long-term metabolic complications, this procedure was described by D. Johnson in $1987 .{ }^{53}$ A circular stapler is used to create a hole in the antrum region, and a linear stapler is used to create a gastric tube on the side of the

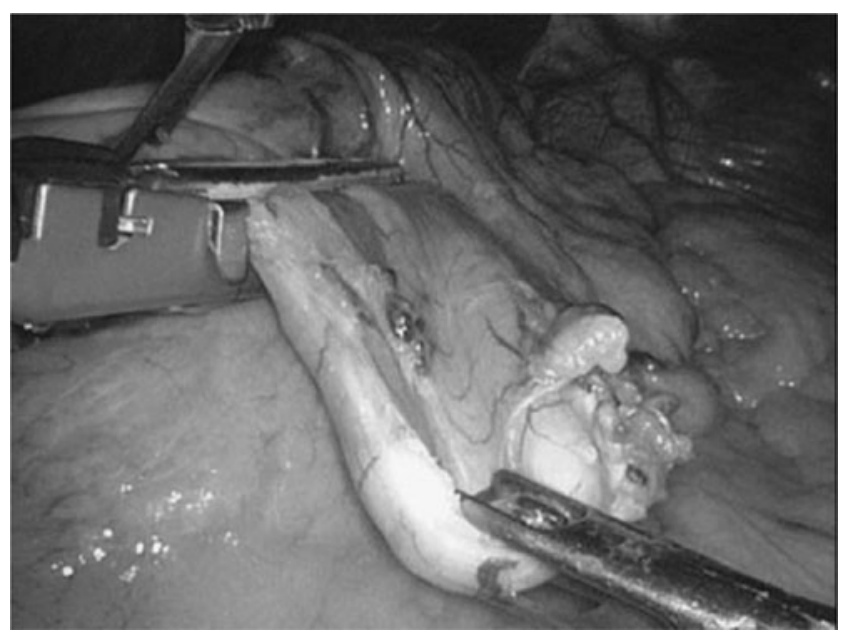

Fig. 7 Intraoperative view of contemporary laparoscopic sleeve gastrectomy. Resection is performed on the side of the greater curvature by the use of a linear stapler along a calibration probe ${ }^{100}$ 
lesser curvature (the Magenstrasse) while dividing the stomach longitudinally in cranial direction. In contrast to "modern" tube gastrectomy, no resection is performed. Because of the preserved antral mill of food, the method is known as the Magenstrasse and Mill operation. The procedure aroused a lot of interest because of its low side effects and marked weight reduction, particularly in the early postoperative phase. ${ }^{53}$

Thus, modern tube gastrectomy may also be regarded as continuation of the Magenstrasse in distal direction with subsequent resection (including the portions of the stomach that produce ghrelin; see the "Discussion" section). The use of tube gastrectomy as a "bridging" step in a two-step surgical procedure is probably one of the most recent developments. Tube gastrectomy is used as an initial intervention in high-risk patients in order to achieve a marked reduction of weight and risk factors and then perform the final intervention. ${ }^{54-56}$

Based on the positive experience gained from this concept and the technical simplicity of the procedure, gastric tube formation was eventually used as a stand-alone and single-step procedure. It is currently being applied to an increasing extent and is also extensively discussed. ${ }^{54,56,57}$

\section{Discussion}

Longitudinal gastric resection in ulcer and bariatric surgery was developed and established for different purposes and apparently, in a mutually independent manner. Nevertheless, achievements in historical ulcer surgery benefited the development of sleeve gastrectomy. Beyond this, resemblance in the development of longitudinal gastric resection and sleeve gastrectomy, respectively, can be demonstrated.

Significant experience with the procedures of segmental gastric resection contributed decisively to increase the understanding of antral innervation and pyloric function. ${ }^{11}$ Side effects like malnutrition, gastric emptying disorders, dumping syndrome following segmental gastric resection, or classical Billroth procedures led to further development of pylorus-preserving gastrectomies providing knowledge of great value about the physiological consequences of resection procedures and vagotomy. ${ }^{58,59}$ Gradually, the complex role of the stomach as storage unit (fundus and oral corpus) and as a mill (distal corpus and antrum) was recognized and the interference with surgical procedures evaluated. ${ }^{60-62}$ Particularly the above-mentioned side effects encouraged O.H. Wangensteen to search for an acceptable operation for ulcer treatment and to introduce tubular or longitudinal gastric resection. ${ }^{11}$ After Wangensteen turned away from the procedure research focusing on longitudinal gastric resection was not abandoned. His successors established a clinically applicable procedure for ulcer treatment despite preserving antral innervation by resection of the greater curvature and thus performing a sleeve gastrectomy.

However, after a brief period of clinical use this procedure faded into insignificance due to the upcoming and widespread conservative treatment options. On closer inspection of the circumstances during introduction of longitudinal gastric resection in bariatric surgery one is initially surprised about remarkable similarities to ulcer surgery. In his article focusing on the introduction of a "new type of gastrectomy" in 1993, P. Marceau described the ulcer genesis in biliopancreatic diversion due to absence of a buffer for gastric secretions. He demanded more physiological gastric emptying while preserving the antrum-pylorus-duodenum segment (in contrast to the procedures used until this time), as well as innervation. Thus, he developed the concept of acid reduction by longitudinal gastric resection. ${ }^{44}$ D.S. and D.W. Hess also emphasized the role of ulcer reduction by longitudinal gastric resection. $^{51}$ Looking at the presented historic development particularly of longitudinal gastric resection and its underlying pathophysiological concept in ulcer surgery, it becomes evident that the procedure is not an entirely new concept of "gastrectomy." Rather, it is a revival of an established method in a different context.

In summary, it may be said that the contribution of ulcer surgery towards the understanding of the gastrointestinal system and particularly its innervation should not be underestimated. Even in recent times we benefit from this knowledge. ${ }^{63}$ Especially bariatric surgery which focuses increasingly on the stomach as target organ obtains valuable information based on already discovered relations. Finally, technological achievements gained from the developing gastric surgery with its initially high mortality and serious complications should be taken into account. While open conventional suture procedures were used initially, surgeons were eager to acquire skills in performing stapler procedures which then became established and were eventually used on a routine basis. Candidates for bariatric surgery are subject to a massively increased risk of mortality and morbidity due to the presence of several obesity-associated concomitant diseases. ${ }^{3}$ Peri- and postoperative risks could be markedly reduced by the introduction of minimally invasive techniques and the fact that they became established standard procedures over time. ${ }^{5,52,64}$

A closer look on longitudinal resection of the greater curvature is indicated. In ulcer surgery and early bariatric surgery, the resection was performed in order to reduce active parietal cells and not primarily as a restrictive step. However, already Wangensteen observed patients losing weight following tubular gastric resection even though he 
tried to create a gastric reservoir by performing transverse gastroplasty. ${ }^{11}$ Gradually the value of restriction was identified and especially one further important function of the resected gastric tissue. Resection of the fundus, which produces ghrelin, and additional reduction of gastric volume with dilatation of the antrum exert a marked positive impact on the sensation of satiety and reduction of calorie intake. ${ }^{54,65,66}$ Ghrelin plays a central role in modulating appetite and the feeling of satiety, influencing gastrointestinal motility, particularly, body weight regulation. Consequently, both ghrelin agonists as prokinetics to treat gastroparesis and postoperative ileus and ghrelin antagonists in order to suppress appetite and to improve glycemic control are subject of intensive research. ${ }^{67}$ The effects of longitudinal gastric resection on the gastrointestinal hormone interplay are far from being sufficiently discovered. Obviously, the hormonal effects are regulated in a complex manner involving among others AgRp, neuropeptide Y, and leptin. ${ }^{68}$ The important role of these hormonal relations and their influence on metabolic disorders like diabetes is reflected by the increasing use of the term metabolic surgery.

Bariatric surgery is undisputedly one of the cornerstones of the treatment of morbid obesity and is subdivided into a number of different procedures. ${ }^{3}$ Traditionally their success is measured in terms of "excess weight loss." Procedures with a malabsorptive component appear to be superior to others. However, the anticipated weight loss should not be the sole or even principal criterion for selection of a procedure. Complications related to the procedures of bariatric surgery are of substantial magnitude and must always be taken into account. The complexity of the surgical techniques and the potential surgical and metabolic complications of the various procedures are inversely related to the anticipated course of weight loss. ${ }^{5}$ Especially malabsorptive and combined procedures are technically demanding and associated with increased rates of morbidity and mortality in high-risk patients. Postoperatively they are frequently associated with deficiency syndromes that require supplementation. ${ }^{69-71}$ Gastro-gastric fistulas can now be largely avoided by complete division of the stomach. However, like leakage of the anastomosis, gastro-gastric fistulas still are a part of the spectrum of complications. ${ }^{72,73}$ Depending on their severity and the time point of diagnosis, leakage of the anastomosis and strictures can be largely treated by the minimal-invasive approach and the use of stents. However, insufficiency of the duodenal stump after duodenal switch, relevant hemorrhage from clip sutures, or insufficiencies associated with concomitant cardiovascular reactions (particularly tachycardia as a warning sign) are serious complications that often require timely revision. ${ }^{52,57,74}$ By modifications such as combined bilio- pancreatic diversion and sleeve gastrectomy, side effects like dumping syndromes or ulcers could be largely avoided over time, but still do occur especially in cases of gastric bypass. ${ }^{51,75,76}$ Furthermore, extensive procedures favor the occurrence of obstructions, hernia, or inappropriate bacterial colonization of the intestines. ${ }^{77,78}$

Purely restrictive procedures such as laparoscopic insertion of an adjustable gastric band are convincing at first glance because of their low perioperative morbidity and mortality rates, but bear the risk of band dislocation (slippage), band migration, port complications, and also compliance-related late complications. ${ }^{42,79}$

Due to these numerous risks and complications, a procedure like sleeve gastrectomy which apparently can be performed easily and has a favorable risk-benefit ratio would appear to have arrived at the right moment. The renaissance, and the enormously rapid and widespread application of this method as a single-step procedure, is quite understandable. ${ }^{80}$ Introduced as a stepwise mode of treatment, the procedure reduced the previously high mortality rates in high-risk patients $(>6 \%$ with a BMI $>$ $60 \mathrm{~kg} / \mathrm{m}^{2}$ ). As single-step procedure, it was convincing because of its low complication (about 9\%) and mortality rates $(<1 \%)$, as well as its low rate of gastrointestinal long-term side effects. ${ }^{81-83}$ Some authors give preference to sleeve gastrectomy as opposed to a gastric balloon as part of a stepwise treatment regimen in high-risk patients. ${ }^{84}$ Analogous to the concept of the Magenstrasse and Mill operation, gastric tube formation avoids malabsorption and implant-related complications while ensuring physiological gastric emptying. ${ }^{54,81}$ In contrast, sleeve gastrectomy involves irreversible resection of parts of the fundus and the corpus. The humoral aspect of the procedure seems to be important (see above). In trials, sleeve gastrectomy was found to achieve a mean excess weight loss of $33 \%$ to $83 \% 1$ year after surgery. ${ }^{54}$ Despite this wide range, it may be assumed that, even in the midterm, the procedure is associated with a similar marked reduction of weight as the usual procedures while reducing obesity-associated concomitant diseases. ${ }^{85,86}$ If additional weight reduction is required subsequently, the procedure can be performed in a two-step manner with a malabsorptive component (gastric bypass or biliopancreatic diversion), either in a combined manner or a repeat sleeve gastrectomy can be conducted. ${ }^{87,88}$

Therefore, one is easily inclined to regard tube gastrectomy as the desired all-round procedure. However, sleeve gastrectomy is also not the sought-after ideal solution. When assessing the procedures carefully, one should consider the fact that longitudinal gastric resection on the side of the greater curvature is an irreversible step and is associated with placement of a long row of stapler sutures along a gastric wall of varied structure. ${ }^{54,89}$ The most 
frequent surgical complications of the procedure are leaks (about $0.9 \%$ ), strictures (about $0.7 \%$ ), and postoperative bleeding (about $0.4 \%$ ). Revision rates are reported to be around $4 \% .{ }^{81,82}$ In addition to intraoperative inspection of the sutures, for instance by endoscopy or the use of methylene blue, several authors recommend oversewing the row of clip sutures or the use of clip reinforcement. ${ }^{56,57,90}$ However, procedures of suture reinforcement or oversewing are controversially discussed. Some authors express apprehensions about suture weakening, do not necessarily attribute the reduction of insufficiency rates to suture reinforcement, or warn against strictures due to oversewing. ${ }^{89,91}$ Other authors recommend laparoscopic greater curvature plication in order to avoid gastric resection and associated complications. ${ }^{92}$

Two factors deserve attention: firstly, a growing number of studies have been focused on the use of sleeve gastrectomy as a single-step procedure and report convincing results, although adequate evaluable long-term results ( $>5$ years) are not yet available. ${ }^{56,83,93}$ Secondly, sleeve gastrectomy is not performed in a standardized manner: various tube diameters and calibration probes (32 to 60 French) are used. ${ }^{68,80,94}$ Besides, the extent of resection, particularly in respect of preservation/resection of the antrum varies. ${ }^{57,95}$ Intraoperative measurement of the volume of the resected stomach is of great importance. A removed volume $<500 \mathrm{~cm}^{3}$ is apparently associated with an early weight regain. ${ }^{57}$ Thus, the results of various workgroups must be compared with caution. Currently, the surgeon also is a substantial factor influencing the outcome of the procedure.

Any person involved in the treatment of obese patients should be aware of the fact that bariatric surgery is a domain of complex interventions in high-risk patients. $^{3}$ The ideal procedure does not exist. Rather, the key to successful treatment lies in a careful assessment of the individual risk jointly by the surgeon and the patient, as well as in providing intensive care and information before the operation and particularly in the long-term after a bariatric operation. ${ }^{5,96}$ Eating habits, baseline weight, the anticipated weight loss, comorbidities, gender, age, and compliance are some of the numerous factors that must be taken into account. ${ }^{5,97} \mathrm{~A}$ team experienced in handling a wide spectrum of bariatric operations with confidence is indispensable to perform successful obesity surgery with sustained enhancement of quality of life and life expectancy. ${ }^{98}$

Particularly sleeve gastrectomy should be viewed separately and not as a universal procedure. In view of the above-mentioned criteria, the procedure certainly is an attractive treatment option. However, it should be performed in a more standardized manner and with due regard to future long-term results.
Open Access This article is distributed under the terms of the Creative Commons Attribution Noncommercial License which permits any noncommercial use, distribution, and reproduction in any medium, provided the original author(s) and source are credited.

\section{References}

1. World Health Organization. Obesity: preventing and managing the global epidemic. Report of a WHO consultation. WHO Tech Rep Ser 2000; 894: 1-253

2. Buchwald H, Buchwald JN. Evolution of operative procedures for the management of morbid obesity 1950-2000. Obes Surg 2002; 12: 705-717

3. Colquitt JL, Picot J, Loveman E, et al (2009) Surgery for obesity. Cochrane Database Syst Rev 15: CD003641

4. Adams KF, Schatzkin A, Harris TB et al. Overweight, obesity, and mortality in a large prospective cohort of persons 50 to 71 years old. N Engl J Med 2006; 355: 763-78

5. Fried M, Hainer V, Basdevant $A$ et al. Inter-disciplinary European guidelines on surgery of severe obesity. Int J Obes 2007; 31: 569-577

6. American Society for Bariatric Surgery, Society of American Gastrointestinal Endoscopic Surgeons. Guidelines for laparoscopic and open surgical treatment of morbid obesity. Obes Surg 2000; 10: 378-379

7. Buchwald H, Estok R, Fahrbach K et al. Weight and type 2 diabetes after bariatric surgery: a systemic review and metaanalysis. Am J Med 2009; 122: 248-256

8. Christou NV, Sampalis JS, Liberman M et al. Surgery decreases long-term mortality, morbidity, and health care use in morbidly obese patients. Ann Surg 2004; 240: 416-423

9. O'Brien PE, Dixon JB, Laurie C et al. Treatment of mild to moderate obesity with laparoscopic adjustable gastric banding or an intensive medical program: a randomized trial. Ann Intern Med 2006; 144: 625-33

10. Crocker MK, Yanovski JA. Pediatric obesity: etiology and treatment. Endocrinol Metab Clin North Am 2009; 38: 525-548

11. Wangensteen $\mathrm{OH}$. Evolution and evaluation of an acceptable operation for peptic ulcer. Am J Gastroenterol 1953; 20: 611-626

12. Spiegel HU, Hauss J, Langhans $P$ et al. Longitudinal resection of the stomach (abstract). J Invest Surg 1990; 3: 292

13. Moiseev AY, Belikov AM. Resection of parietal cells in the treatment of duodenal ulcer. Chirurgika Moskva 1990; 12: 42-44

14. Péan JE. De l'ablation des tumeurs de l'estomac par la gastrectomie. Gaz Hôp 1879; 60: 473

15. Rydygier L. Die erste Magenresektion beim Magengeschwür. Zbl Chir 1882; 12: 198-9

16. Billroth T. Offenes Schreiben an Herrn Dr. L. Wittelschöfer. Wien Med Wochenschr 1881; 31: 161

17. Schwarz K. Über penetrierende Magen- und Jejunalgeschwüre. Bruns Beiträge Klin Chir 1910; 67: 96-112

18. Mikulicz J. Die chirurgische Behandlung des chronischen Magengeschwürs. Berl Klin Wochenschr 1897; 34: 561

19. Riedel B. Quere Magenresektion. Arch klin Chir 1904; 74: 572581

20. Connell FG. Fundectomy: A new principle in the treatment of gastric or duodenal ulcer. Surg Gynecol Obstet 1929; 49: 696701

21. Wangensteen $\mathrm{OH}$. Segmental gastric resection for peptic ulcer, method permitting restoration of anatomic continuity. J Am Med Assoc 1952; 149: 18-23

22. Ferguson DJ. Segmental gastrectomy with innervated antrum for duodenal ulcer. Results at one to five years. Surgery 1960; 47: $548-556$ 
23. Largiadèr F. Segmentäre Magenresektion und Vagotomie bei Ulcus duodeni. Schweiz Med Wschr 1921; 101: 1204-7

24. Sekine T. An evaluation of segmental gastrectomy for gastric ulcer. One to ten year follow-up. Surgery 1975 ; 78: 508-514

25. Wangensteen OH, Varco RL, Hay L et al. Gastric acidity before and after operative procedure with special reference to the role of the pylorus and the antrum. Ann Surg 1940; 112: 626-670

26. Neugebauer F. Die Längsresektion des Magens bei hochsitzendem Ulcus der kleinen Kurvatur. Beiträge zur klinischen Chirurgie 1921; 122: 369-385

27. Strauss AA. Longitudinal resection of the lesser curvature with resection of pyloric sphincter for gastric ulcer: An experimental and clinical study. JAMA 1924; 31: 1765-1770

28. Schmieden V. Über die Exzision der Magenstraße (Grundsätzliches zur Operation des Magengeschwürs). Zbl Chir 1921; 48: $1534-1538$

29. Wangensteen OH. Aseptic gastric resection. SGO 1940; 70: 5970

30. Wangensteen $\mathrm{OH}$. Segmental gastric resection - an acceptable operation for peptic ulcer; Tubular resection unacceptable. Surgery 1957; 41: 686-690

31. Leger L, Kanoui F. La gastrectomie fundique. Une orientation possible du traitement chirurgical de la maladie ulcéreuse. Presse Med 1953; $61: 962-964$

32. Deloyers L. Proposition et justification d'une intervention curatrice nouvelle de la maladie ulcéreuse. La gastrectomie inversée. Lyon Chir 1955; 50: 5-15

33. Saegesser M. Die operativen Maßnahmen bei Ulcus pepticum. Die "ideale" Magenresektion. In: Saegesser M, ed. Der Ulkus Magen. Bern: Huber Verlag 1966: 70-72

34. Hauss J, Spiegel HU, Langhans $P$ et al. Pyloric-preserving longitudinal resection of the stomach-an "ideal" method of resection? Chirurgisches Forum $\mathrm{f}$ exp u klin Forschung 1988: 432-436

35. Spiegel HU. Die Magenlängsresektion als alternatives chirurgisches Therapieverfahren zur Ulkusbehandlung? Eine funktionelle und morphologische Studie. Habilitationsschrift Muenster 1993

36. Bünte H. Das digestorische System. In Bünte H, ed. Chirurgie. Naturwissenschaft und Handwerk. München: Urban und Schwarzenberg 1996: 457

37. Kremen AJ, Linner JH, Nelson CH. An experimental evaluation of the nutritional importance of proximal and distal small intestine. Ann Surg 1954; 140: 439-48

38. Salameh JR. Bariatric Surgery: Past and Present. Am J Med Sci 2006; 331: 194-200

39. Griffen WO Jr, Bivins BA, Bell RM. The decline and fall of the jejunoileal bypass. Surg Gynecol Obstet 1983; 157: 301-8

40. Mason EE, Ito C. Gastric bypass in obesity. Surg Clin North Am 1967; 47: 1345-51

41. Griffen WO, Young VL, Stevenson CC. A prospective comparison of gastric and jejunoileal bypass operation for morbid obesity. Ann Surg 1977; 186: 500-507

42. Tice JA, Karliner L, Walsh J et al. Gastric banding or bypass? A systemic review comparing the two most popular bariatric procedures. Am J Med 2008; 121: 885-93

43. Scopinaro N, Gianetta E, Civalleri D et al. Bilio-pancreatic bypass for obesity: II. Initial experience in man. Br J Surg 1979; 66: 618-620

44. Marceau P, Biron S, Bourque RA et al. Biliopancreatic diversion with a new type of gastrectomy. Obes Surg 1993; 3: 29-35

45. Livingston EH. Obesity and its surgical management. Am J Surg 2002; 184: 103-113

46. Printen KJ, Mason EE. Gastric surgery for relief of morbid obesity. Arch Surg 1973; 106: 428-31

47. Mason EE. Vertical banded gastroplasty for obesity. Arch Surg 1982; 117: 701-706
48. Wilkinson LH, Peloso OA. Gastric (reservoir) reduction for morbid obesity. Arch Surg 1981; 116: 602-605

49. Kuzmak LI. Silicone gastric banding: a simple and effective operation for morbid obesity. Contemp Surg 1986; 28: 13-8

50. DeMeester TR, Fuchs KH, Ball CS et al. Experimental and clinical results with proximal end-to-end duodenojejunostomy for pathologic duodenogastric reflux. Ann Surg 1987; 206: 414-24

51. Hess DS, Hess DW. Biliopancreatic diversion with a duodenal switch. Obes Surg 1998; 8: 267-282

52. Ren CJ, Patterson E, Gagner M. Early results of laparoscopic biliopancreatic diversion with duodenal switch: a case series of 40 consecutive patients. Obes Surg 2000; 10: 514-23

53. Johnston D, Dachtler J, Sue-Ling HM et al. The Magenstrasse and Mill Operation for Morbid Obesity. Obes Surg 2003; 13: 10 16

54. Akkary E, Duffy A, Bell R. Deciphering the Sleeve: Technique, indications, efficacy, and Safety of Sleeve Gastrectomy. Obes Surg 2008; 18: 1323-1329

55. Regan JP, Inabnet WB, Gagner $M$ et al. Early experience with two-stage laparoscopic Roux-en-Y gastric bypass as an alternative in the super-super obese patient. Obes Surg 2003; 13: 861-4

56. Tucker ON, Szomstein S, Rosenthal RJ. Indications for sleeve gastrectomy as a primary procedure for weight loss in the morbidly obese. J Gastrointest Surg 2008; 12: 662-7

57. Weiner RA, Weiner S, Pomhoff I et al. Laparoscopic sleeve gastrectomy-influence of sleeve size and resected gastric volume. Obes Surg 2007; 17: 1297-1305

58. Stockbrügger RW. Postoperative gastrointestinale Motilitätsstörungen, Teil 1: Folgezustände nach Abdominalchirurgie allgemein und nach Ulkuschirurgie. Fortschr Med 1988; 106: 590-592

59. Maki T, Shiratori T, Hatafuku $T$ et al. Pylorus-preserving gastrectomy as an improved operation for gastric ulcer. Surgery 1967; 61: 838-45

60. Richter HM. Physiologic consequences of vagotomy and gastric resection. Gastroenterol Clin North Am 1994; 23: 193-213

61. Behrns KE, Sarr MG. Diagnosis and management of gastric emptying disorders. Adv Surg 1994; 27: 233-55

62. Braasch JW, Brooke-Cowden GL. Disability after gastric surgery. Surg Clin North Am 1976; 56: 607-13

63. Holle GE. Pathophysiology and modern treatment of ulcer disease. Int J Mol Med 2010; 25: 483-91

64. Korenkov M, Sauerland S. Clinical update: bariatric surgery. Lancet 2007; 370: 1988-90

65. Karamanakos SN, Vagenas K, Kalfarentzos F et al. Weight loss, appetite suppression, and changes in fasting and postprandial ghrelin and peptide-YY levels after Roux-en-Y gastric bypass and sleeve gastrectomy: a prospective, double blind study. Ann Surg 2008; 247: 401-7

66. Langer FB, Reza Hoda MA, Bohdjalian A et al. Sleeve gastrectomy and gastric banding: effects on plasma ghrelin levels. Obes Surg 2005; 15: 1024-9

67. Camilleri M, Papathanasopoulos A, Odunsi ST. Actions and therapeutic pathways of ghrelin for gastrointestinal disorders. Nat Rev Gastroenterol Hepatol 2009; 6: 343-52

68. Papailiou J, Albanopoulos K, Toutouzas KG et al. Morbid obesity and sleeve gastrectomy: how does it work? Obes Surg 2010; 11: Epub ahead of print

69. Fernandez AZ Jr, Demaria EJ, Tichansky DS et al. Experience with over 3,000 open and laparoscopic bariatric procedures: multivariate analysis of factors related to leak and resultant mortality. Surg Endosc 2004; 18: 193-7

70. O'Rourke RW, Andrus J, Diggs BS et al. Perioperative morbidity associated with bariatric surgery: an academic center experience. Arch Surg 2006; 141: 262-8

71. Malinowski SS. Nutritional and metabolic complications of bariatric surgery. Am J Med Sci 2006; 331: 291-25 
72. Carrodeguas L, Szomstein S, Soto F et al. Management of gastrogastric fistulas after divided Roux-en-Y gastric bypass surgery for morbid obesity: analysis of 1,292 consecutive patients and review of literature. Surg Obes Relat Dis 2005; 1: 467-74

73. Bell BJ, Bour ES, Scott JD et al. Management of complications after laparoscopic Roux-en-Y gastric bypass. Minerva Chir 2009; 64: 265-76

74. Eisendrath P, Cremer M, Himpens J et al. Endotherapy including temporary stenting of fistulas of the upper gastrointestinal tract after laparoscopic bariatric surgery. Endoscopy 2007; 39: 625-30

75. Kellogg TA, Bantle JP, Leslie DB et al. Postgastric bypass hyperinsulinemic hypoglycemia syndrome: characterization and response to a modified diet. Surg Obes Relat Dis 2008; 4: 492-9

76. Rasmussen JJ, Fuller W, Ali MR. Marginal ulceration after laparoscopic gastric bypass: an analysis of predisposing factors in 260 patients. Surg Endosc 2007; 21: 1090-4

77. Abell TL, Minocha A. Gastrointestinal complications of bariatric surgery: diagnosis and therapy. Am J Med Sci 2006; 331: 214-8

78. Paroz A, Calmes JM, Giusti Vet al. Internal hernia after laparoscopic Roux-en-Y gastric bypass for morbid obesity: a continuous challenge in bariatric surgery. Obes Surg 2006; 16: 1482-7

79. Toouli J, Kow L, Ramos AC et al. International multicenter study of safety and effectiveness of Swedish adjustable gastric band in 1-, 3-, and 5-year follow-up cohorts. Surg Obes Relat Dis 2009; 5: 598-609

80. Gagner M, Deitel M, Kalberer TL et al. The second international consensus summit for sleeve gastrectomy, March 19-21, 2009. Surg Obes Relat Dis 2009; 5: 476-85

81. Gumbs AA, Gagner M, Dakin G et al. Sleeve gastrectomy for morbid obesity. Obes Surg 2007; 17: 962-969

82. Frezza EE, Reddy S, Gee LL et al. Complications after sleeve gastrectomy for morbid obesity. Obes Surg 2009; 19: 684-7

83. Menenakos E, Stamou KM, Albanopoulos K et al. Laparoscopic sleeve gastrectomy performed with intent to treat morbid obesity: a prospective single-center study of 261 patients with a median follow-up of 1 year. Obes Surg 2010; 20: 276-82

84. Milone L, Strong V, Gagner M. Laparoscopic sleeve gastrectomy is superior to endoscopic intragastric balloon as a first stage procedure for super-obese patients (BMI $>$ or $=50$ ). Obes Surg 2005; 15: 612-7

85. Todkar JS, Shah SS, Shah PS et al. Long-term effects of laparoscopic sleeve gastrectomy in morbidly obese subjects with type 2 diabetes mellitus. Surg Obes Relat Dis 2010; 6: 142-5
86. Vidal J, Ibarzabal A, Romero F et al. Type 2 diabetes mellitus and the metabolic syndrome following sleeve gastrectomy in severely obese subjects. Obes Surg 2008; 18: 1077-82

87. Langer FB, Bohdjalian A, Felberbauer FX et al. Does gastric dilatation limit the success of sleeve gastrectomy as a sole operation for morbid obesity? Obes Surg 2006; 16: 166-71

88. Baltasar A, Serra C, Pérez N et al. Re-sleeve gastrectomy. Obes Surg 2006; 16: 1535-8

89. Baker RS, Foote J, Kemmeter P et al. The science of stapling and leaks. Obes Surg 2004; 14: 1290-8

90. Consten EC, Gagner M, Pomp A et al. Decreased bleeding after laparoscopic sleeve gastrectomy with or without duodenal switch for morbid obesity using a stapled buttressed absorbable polymer membrane. Obes Surg 2004; 14: 1360-6

91. Chen B, Kiriakopoulos A, Tsakayannis D et al. Reinforcement does not necessarily reduce the rate of staple line leaks after sleeve gastrectomy. A review of the literature and clinical experiences. Obes Surg 2009; 19: 166-72

92. Ramos A, Galvao Neto M, Galvao M et al. Laparoscopic greater curvature plication: initial results of an alternative restrictive bariatric procedure. Obes Surg 2010; 20: 913-8

93. Fuks D, Verhaeghe P, Brehant O et al. Result of laparoscopic sleeve gastrectomy: a prospective study in 135 patients with morbid obesity. Surgery 2009; 145: 106-13

94. Dapri G, Vaz C, Cadière GB et al. A prospective study comparing two different techniques for laparoscopic sleeve gastrectomy. Obes Surg 2007; 11: 1435-41

95. Baltasar A, Serra C, Pérez N et al. Laparoscopic sleeve gastrectomy: a multi-purpose bariatric operation. Obes Surg 2005; 15: 1124-8

96. Shen R, Dugay G, Rajaram K et al. Impact of patient follow-up on weight loss after bariatric surgery. Obes Surg 2004; 14 : 514-9

97. Buchwald H. A bariatric surgery algorithm. Obes Surg 2002; 12 : 733-46

98. Hollenbeak CS, Rogers AM, Barrus B et al. Surgical volume impacts bariatric surgery mortality: a case for centers of excellence. Surgery 2008; 144: 736-43

99. Scopinaro N, Gianetta E, Civalleri D et al. Bilio-pancreatic bypass for obesity: I. An experimental study in dogs. Br J Surg 1979; 66: 613-617

100. Weiner RA. Adipositas-chirurgische Therapieprinzipien. Chirurg 2008; 79: 826-836 